\title{
Enzymatic Biodiesel Synthesis Using a Byproduct Obtained from Palm Oil Refining
}

\author{
Igor Nascentes dos Santos Corrêa, ${ }^{1}$ Susana Lorena de Souza, ${ }^{1}$ Marly Catran, ${ }^{1}$ \\ Otávio Luiz Bernardes, ${ }^{1}$ Márcio Figueiredo Portilho, ${ }^{2}$ and Marta Antunes Pereira Langone ${ }^{1}$ \\ ${ }^{1}$ Institute of Chemistry, Rio de Janeiro State University, Rua São Francisco Xavier 524, PHLC/IQ sala 310, Rio de Janeiro, \\ RJ 20550-013, Brazil \\ ${ }^{2}$ Cenpes, Petrobras, Rio de Janeiro, RJ 21949-900, Brazil
}

Correspondence should be addressed to Marta Antunes Pereira Langone, langone@uerj.br

Received 12 November 2010; Revised 3 March 2011; Accepted 24 March 2011

Academic Editor: Lucia Gardossi

Copyright (C) 2011 Igor Nascentes dos Santos Corrêa et al. This is an open access article distributed under the Creative Commons Attribution License, which permits unrestricted use, distribution, and reproduction in any medium, provided the original work is properly cited.

\begin{abstract}
An alternative route to produce biodiesel is based on esterification of free fatty acids present in byproducts obtained from vegetable oil refining, such as palm oil fatty acid distillate (PFAD). PFAD is a byproduct of the production of edible palm oil, which contains $96 \mathrm{wt} . \%$ of free fatty acids. The purpose of this work was to study biodiesel synthesis via esterification of PFAD with methanol and ethanol, catalyzed by commercial immobilized lipases (Novozym 435, Lipozyme RM-IM, and Lipozyme TL-IM), in a solvent-free system. The effects of reaction parameters such as type of lipase, enzyme amount, type of alcohol, alcohol amount, and enzyme reuse were studied. Fatty acid conversion of $93 \%$ was obtained after $2.5 \mathrm{~h}$ of esterification reaction between PFAD and ethanol using $1.0 \mathrm{wt} . \%$ of Novozym 435 at $60^{\circ} \mathrm{C}$.
\end{abstract}

\section{Introduction}

Biodiesel is defined as monoalkyl esters of long chain fatty acids, preferentially methyl and ethyl esters, derived from renewable feedstock, such as vegetable oils or animal fats [1]. Biodiesel is a biodegradable and nonpolluting fuel that has received increasing attention in the recent past. However, the major barrier for the commercialization of biodiesel is its high manufacturing cost [2]. An alternative route to produce biodiesel is based on esterification of free fatty acids present in high concentrations in byproducts obtained from vegetable oil refining [3]. Deodorizer distillates and soapstock are the major byproducts from vegetable oil refining. They have little commercial value and are sold at a fraction of the oil cost [4].

Considering the increase of edible oils production caused by the enhancing of biodiesel production and the human population increase [4], it is necessary to investigate uses for these byproducts in order to avoid their discharge on the environment and produce potential high-value products as well.

In these way, the majority of the published research focuses on the recuperation of high-value chemicals such as tocopherols and sterols from vegetable oil deodorizer distillates (VODD) [5-9]. Notwithstanding, there are also publications about the use of this feedstock to biodiesel synthesis [3, 10-14].

The composition of deodorizer distillates varies widely as it depends on several factors including the raw material and the conditions of the oil refining process $[6,9]$. Usually, the free fatty acids content in VODD varies between 25 and $75 \%[9,11]$. For example, the palm oil fatty acid distillates (PFAD) is a byproduct of physical refining of crude palm oil and is composed mainly of free fatty acids $(\sim 82 \%)$ with smaller amounts of glycerol esters and nonglyceride components (vitamin E, squalene, and phytosterols) [15]. It is estimated that the total production of PFAD represents $4 \%$ of crude palm oil production and the average monthly 
export price of PFAD in 2008 was 501 (range 302-730) (FOB USD/Tonne) [15].

Conversion of free fatty acids (FFA) present in VODD to fatty acid alkyl esters can be performed by esterification reactions using lipases as biocatalysts:

$\mathrm{FFA}+$ alcohol $\longrightarrow$ fatty acid alkyl esters (biodiesel) + water.

Enzyme-based processes are carried out under mild reaction conditions that reduce energy cost as well as tend to have lower waste treatment costs [16]. Furthermore, the reuse of immobilized enzymes is possible, minimizing costs and turning these processes economically available [17].

Following the alternative current trend to develop environmentally acceptable use for byproducts from vegetable oil refining, the aim of this work is to produce biodiesel by the esterification reaction of fatty acids from PFAD with short-chain alcohols using immobilized commercial lipases. The effects of reaction parameters such as type of enzyme, enzyme amount, type of alcohol, alcohol amount, and enzyme reuse were investigated.

\section{Materials and Methods}

2.1. Materials. PFAD from palm oil refining process was provided by Piraquê S.A. (Brazil). Commercial immobilized lipases used were Lipozyme RM-IM (lipase from Rhizomucor miehei), Lipozyme TL-IM (lipase from Thermomyces lanuginosus), and Novozym 435 (lipase from Candida antarctica), all kindly donated by Novozymes Latin America Ltda. (Araucária, Brazil). Methanol (P.A.), ethanol (P.A.), butanol (P.A.), acetone (P.A.), and n-hexane (99\%) were obtained from Vetec Química Fina Ltda (Rio de Janeiro, Brazil). Oleic acid (extra pure) was purchased from Merck (Darmstadt, Germany).

2.2. PFAD Characterization. Acidity and acid value of PFAD were determined according to AOCS Te 1a-64 [18]. Iodine index and moisture content were determined according to AOCS Cd 1d-64 and Ca 2e-84 [18], respectively. Fatty acids present in PFAD were determined according to AOCS Ce 1f-96 [18], using an HP 6890N GC equipped with a flame ionization detector and capillary column SP 2340.

2.3. Measurement of Lipases Activities. The esterification activity of commercial lipases, Lipozyme RM-IM, Lipozyme TL-IM, and Novozym 435, was measured by the consumption of oleic acid at $45^{\circ} \mathrm{C}$ in the esterification reaction with butanol (oleic acid/butanol molar ratio of 1) with the enzyme amount of $3 \mathrm{wt} . \%$. One esterification unit was defined as the amount of enzyme that consumed $1 \mu$ mole of oleic acid per minute (U) per $g$ of enzymatic preparation under the experimental conditions described herein. The esterification activities of commercial lipases, Lipozyme RMIM, Lipozyme TL-IM and Novozym 435, were 1,510, 454, and 2,960 $\left(\mu\right.$ moles of acid $\left.\cdot \min ^{-1} \cdot \mathrm{g}^{-1}\right)$, respectively.
2.4. Esterification Reaction. Esterification reactions took place in a closed $15 \mathrm{~mL}$ batch reactor magnetically stirred, coupled to a condenser in order to avoid alcohol loss. Water circulating in the condenser was cooled by a thermostatic bath. Reacting medium temperature $\left(60^{\circ} \mathrm{C}\right)$ was kept constant by circulating hot ethylene glycol through the reactor jacket. A thermostatic bath (Haake DC30) allowed a close control over the process temperature. The mass of PFAD was always $8 \mathrm{~g}$ while the alcohol mass ranged between 1 and $4 \mathrm{~g}$. The alkyl esters (biodiesel) synthesis was evaluated as a function of the type of lipase (Novozym 435, Lipozyme RM-IM, and Lipozyme TL-IM), enzyme amount (0.1, 0.5, $1,1.5,3,4.5,6,7.5$, and 9 wt.\% based on PFAD mass), and type of alcohol used (methanol or ethanol) and in respect to stepwise addition of alcohol (single addition, at time 0 , or two consecutive alcohol additions, i.e., 1/2 of alcohol added at time 0 and $1 / 2$ after 30 minutes).

2.5. Quantification of Free Fatty Acids (FFAs). Reaction progress was monitored by taking duplicate samples $(100 \mu \mathrm{L})$ each $30 \mathrm{~min}$ until $2.5 \mathrm{~h}$ of reaction. The amount of FFAs in reaction medium samples was analyzed by titration with $\mathrm{NaOH} 0.02 \mathrm{~mol} \cdot \mathrm{L}^{-1}$ using a Mettler DL 25 autotitrator. Conversion was defined as the number of moles of fatty acids reacted per mole of fatty acids fed to the system.

2.6. Chromatography Analysis (Biodiesel Yield). The fatty acid methyl esters (FAME) and fatty acid ethyl esters (FAEE) content in the reaction medium was analyzed on Varian gas chromatograph (CP-3380 model), equipped with a flame ionization detector (FID), a CP WAX 52 CB capillary column $30 \mathrm{~m} \times 0.25 \mathrm{~mm} \times 0.25 \mathrm{~mm}$, and a split injection system with a $1: 20$ ratio. Injector and detector temperatures were kept at 280 and $300^{\circ} \mathrm{C}$, respectively. The oven was initially maintained at $200^{\circ} \mathrm{C}$ for $4.5 \mathrm{~min}$, then heated up to $250^{\circ} \mathrm{C}$ at a $20^{\circ} \mathrm{C} \mathrm{min}^{-1}$ rate, and kept constant at the final temperature for $5 \mathrm{~min}$. Hydrogen was used as the carrier gas at a $2 \mathrm{~mL} \mathrm{~min}^{-1}$ flow rate; column pressure was set at 20 psi. A computer loaded with the Star Workstation 6.2 software was connected to the GC by a Star 800 Module Interface to automatically integrate the peaks obtained. Methyl heptadecanoate was used as internal standard. The yield of biodiesel was calculated as grams of biodiesel produced per grams of PFAD.

2.7. Enzyme Reuse. The enzyme reuse was evaluated in the esterification reaction of PFAD with alcohol (methanol, ethanol) at $60^{\circ} \mathrm{C}$, with the enzyme concentration of $3 \mathrm{wt} . \%$. The alcohol was added in a stepwise manner $\left(T_{0}=0.5 \mathrm{~g}\right.$, $T_{30 \mathrm{~min}}=0.5 \mathrm{~g}$ ). The enzyme was separated from the reaction medium by decantation, washed with n-hexane, vacuum filtered, and placed in a desiccator for $24 \mathrm{~h}$. After this treatment, the enzyme was reused in a new batch.

\section{Results and Discussion}

3.1. PFAD Characterization. The byproducts from vegetable oil refining process are complex mixtures, and there are 
TABLE 1: Physicochemical properties of PFAD.

\begin{tabular}{lc}
\hline Acidity (wt.\%) (as oleic acid) & 96.3 \\
Acid value $(\mathrm{mg} \mathrm{KOH} / \mathrm{g}$ sample) & 191.6 \\
Iodine index $\left(\mathrm{I}_{2} / 100 \mathrm{~g}\right)$ & 63.8 \\
Moisture content $(\%)$ & 0.70 \\
\hline
\end{tabular}

TABLe 2: Fatty acid composition of PFAD (wt.\%).

\begin{tabular}{lc}
\hline Fatty acid & Composition (\%) \\
\hline Caprilic acid C8 & 0.0 \\
Capric acid C10 & 0.1 \\
Lauric acid C12 & 0.3 \\
Myristic acid C14 & 0.9 \\
Palmitic acid C16 & 46.1 \\
Palmitoleic acid C16:1 & 0.3 \\
Stearic acid C18 & 5.5 \\
Oleic acid C18:1 & 36.6 \\
Linoleic acid C18:2 & 9.2 \\
Linolenic acid C18:3 & 0.3 \\
Arachidic acid C20 & 0.3 \\
Gadoleic acid C20:1 & 0.1 \\
Behenic acid C22 & 0.0 \\
Lignoceric acid C24 & 0.0 \\
Other fatty acids & 0.1 \\
Total trans isomer & 0.2 \\
\hline
\end{tabular}

few publications concerning their full analysis and characterization [4]. PFAD was characterized according to its physicochemical properties (Table 1). Fatty acids are the major components of PFAD. They represent approximately 96\% (as oleic acid) of the PFAD composition on a wet basis (Table 1). This value agrees with the free fatty acid content in the PFAD used by Chongkhong et al. [13], $96 \mathrm{wt} . \%$, and by Top [15], 70-90 wt.\%.

Acid value and iodine index of PFAD are also shown in Table 1. Some chemical properties of raw materials influence biodiesel quality. The iodine index is related to the grade of oil unsaturation, and, in general, its value has to be lower than $115 \%$ for biodiesel production [19]. An iodine index of $63.8 \%$ was determined for the PFAD used in this work (Table 1).

The fatty acid profile of the raw material plays an important role on biodiesel properties. The chemical composition of PFAD regarding fatty acids is shown in Table 2. Palmitic $(46.1 \%)$ and oleic $(36.6 \%)$ acids are predominant in the PFAD studied in this work. The PFAD composition showed in Table 2 is similar to the fatty acid profile of the two samples of PFAD reported by Top [15].

As reported in the literature, fatty acid content of byproducts obtained from vegetable oil refining is a reflection of the parent oil composition [4]. Usually, palm oils contain $44 \%$ of palmitic acid and $39 \%$ of oleic acid [20]. So, the composition showed in Table 2 agrees with the expected values.
3.2. Effects of the Type of Lipase. Methanol is the most used alcohol for biodiesel production, and to a lesser extension, ethanol. As methanol is cheaper and more reactive and the fatty acid methyl esters (FAME) are more volatile than those obtained from ethanol (FAEE, fatty acid ethyl esters), it is chosen [21]. However, considering that Brazil is the largest world producer of ethanol and that ethanol can be considered more renewable because it can be produced from renewable sources by fermentation, the reactions for biodiesel synthesis from PFAD were carried out with methanol and ethanol.

The most widely used commercial immobilized lipases (Novozym 435, Lipozyme RM-IM, and Lipozyme TL-IM) were compared regarding conversion of fatty acids from a PFAD. Reactions were carried out at $60^{\circ} \mathrm{C}$, considering the melting point of PFAD $\left(\sim 50^{\circ} \mathrm{C}\right)$, using $3 \mathrm{wt} . \%$ (based on PFAD weight) of enzyme and $2 \mathrm{~g}$ of alcohol (methanol or ethanol). The alcohol was added in a stepwise manner $\left(T_{0}=\right.$ $1.0 \mathrm{~g}, T_{30 \mathrm{~min}}=1.0 \mathrm{~g}$ ) to avoid high amounts of alcohol in the reaction medium at the beginning of the reaction. According to the results shown in Figure 1, Novozym 435 presented the highest conversion in the presence of methanol (95\%) and ethanol (91\%). These results are expected considering the esterification activity values obtained in this work for the three commercial lipases. The esterification activities of Lipozyme RM-IM, Lipozyme TL-IM, and Novozym 435 were $1,510,454$, and 2,960 $\left(\mu\right.$ moles of acid $\left.\cdot \mathrm{min}^{-1} \cdot \mathrm{g}^{-1}\right)$, respectively. Novozym 435 showed the highest esterification activity. It has been reported as one of the most active and versatile enzyme [3,22-24]. This enzyme shows high stability even in the presence of low-molecular-weight alcohols, like methanol and ethanol.

Besides commercial lipases presented different activities for esterification, conversions of fatty acids showed in Figure 1 may be explained by several reasons. For instance, whereas the reaction was carried out in a batch reactor, one cannot disregard the possible denaturation of enzyme in presence of reagents or products during the reaction time. Moreover, considering the variety of fatty acids present in PFAD, lipases may exhibit different selectivities depending on the number of carbon atoms as well as on the presence of unsaturations in the acid molecule.

Lipozyme RM-IM is also a quite active and stable lipase in anhydrous media and thus has been widely used in esterification reactions [22]. Using this enzyme, a conversion of $52.3 \%$ was obtained with methanol and $53.4 \%$ with ethanol.

Lipozyme TL-IM was less active for the esterification reaction than the other studied lipases. The PFAD conversion values were $28.8 \%$ and $33.1 \%$ in the reactions with methanol and ethanol, respectively. This enzyme shows better performance in transesterification reactions, as reported in literature [22].

Similar results were obtained by Souza et al. [3] in soybean oil deodorizer distillate (SODD) esterification with ethanol using immobilized commercial lipases. Reactions were carried out at $50^{\circ} \mathrm{C}$ using $3 \mathrm{wt} \%$ of enzyme (Novozym 435, Lipozyme TL-IM, and Lipozyme RM-IM) and $2 \mathrm{~g}$ of ethanol $\left(T_{0}=1 \mathrm{~g} ; T_{30} \min =1 \mathrm{~g}\right)$. Novozym 435 presented the 


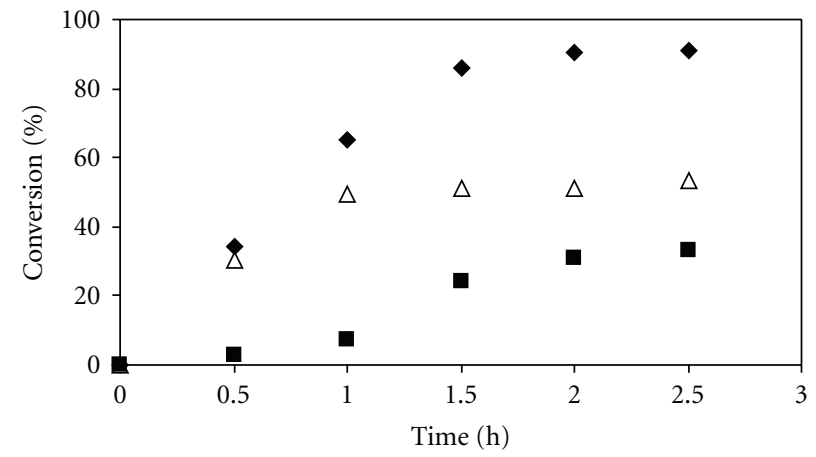

- Novozym 435

$\triangle$ Lipozyme RM-IM

- Lipozyme TL-IM

(a) Methanol

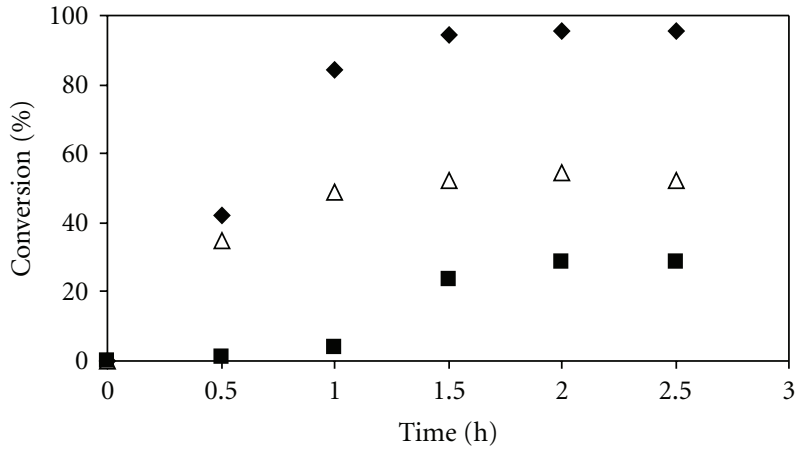

- Novozym 435

$\triangle$ Lipozyme RM-IM

- Lipozyme TL-IM

(b) Ethanol

FIGURE 1: Effects of type of lipase on fatty acids conversion during $2.5 \mathrm{~h}$, using $3 \mathrm{wt} . \%$ of commercial lipase, $8 \mathrm{~g}$ of PFAD, and $2 \mathrm{~g}$ of alcohol added in two steps $\left(T_{0}=1 \mathrm{~g}, T_{30} \min =1 \mathrm{~g}\right)$ at $60^{\circ} \mathrm{C}$. (a) Methanol; (b) ethanol.

highest SODD conversion (83.5\%), while Lipozyme RM and Lipozyme TL-IM showed conversion values equal to 59.1 and 16.4, respectively. The chemical composition of PFAD and SODD (byproducts from vegetable oil refining) regarding fatty acids and lipase selectivity may explain the differences in conversion values observed for the three commercial lipases. Palmitic (46.1\%) and oleic (36.6\%) acids are predominant in the PFAD while in the SODD the predominance of palmitic acid $(30.9 \%)$, followed by oleic acid $(23.8 \%)$ and stearic acid (23.7\%), was observed.

As Lipozyme TL-IM was the less active enzyme tested in this work conditions, the following experiments were carried out using just Lipozyme RM-IM and Novozym 435.

3.3. Effects of the Type and Amount of Alcohol. The effects of initial amount of alcohol and its feeding technique to the reactor (stepwise or single addition) on the fatty acid conversion were investigated. The amount of PFAD was always $8 \mathrm{~g}$ while methanol and ethanol mass ranged between 1 and $4 \mathrm{~g}$. Based on the PFAD composition shown in Table 2, we can admit that the proportion $8 \mathrm{~g}$ of distillate: $1 \mathrm{~g}$ of alcohol corresponds nearly to a molar ratio $1: 1$ of fatty acids to alcohol. So, the PFAD fatty acids would be the limiting reagent.

Figure 2(a) shows that an increase in methanol amount when it was completely added at the beginning of the reaction leads to a decrease in fatty acid conversion for both enzymes. Talakuder et al. [25] also observed that the biodiesel yield in the PFAD esterification reactions drops at a methanol content of more than $13 \mathrm{wt} . \%$ of PFAD. These results are in agreement with those obtained in our work in the reactions using $1 \mathrm{~g}$ of methanol and $8 \mathrm{~g}$ of PFAD (methanol content $=12.5 \mathrm{wt}$. $\%$ of PFAD).

When ethanol was employed, lower conversion values were obtained with increasing concentration of alcohol only for the reactions catalyzed by Lipozyme RM-IM (Figure 2(b)). So, these results show that the destabilizing effect of alcohol on lipases decreased with increasing alcohol molecular weight as previously reported by other authors $[3,22,24]$. Similar results were observed in esterification reactions of ethanol and soybean oil deodorizer distillate [3]. Moreover, loss of lipase activity caused by the polar shortchain alcohols was greater for Lipozyme RM-IM than for Novozym 435 as has already been reported $[23,24]$.

The stepwise addition of alcohol has been the main strategy to avoid lipase denaturation caused by high initial concentration of alcohol. In this system, alcohol concentration in the reaction medium was always kept low and thus reducing enzyme deactivation. As shown in Figure 3(a), higher fatty acid conversion was obtained with stepwise addition of methanol (two consecutive alcohol additions, i.e. $1 / 2$ of alcohol added at time 0 , and 1/2 after 30 minutes). Using ethanol, this effect was not as pronounced for the reactions catalyzed by Novozym 435 (Figure 3(b)). Novozym 435 has a greater resistance to the presence of short-chain alcohols than the immobilized lipase Lipozyme RM-IM. This explains that stepwise addition has a minor impact on the conversion in the case of Novozym 435.

3.4. Effects of Lipase Amount. Effects of enzyme amount on fatty acids conversion were studied using $0.1,0.5,1,1.5,3$, 4.5, 6, 7.5, and $9 \mathrm{wt} . \%$ of enzyme (Lipozyme RM-IM and Novozym 435) at $60^{\circ} \mathrm{C}$, with stepwise addition of $2 \mathrm{~g}$ of alcohol. Results are shown in Figure 4.

When Lipozyme RM-IM was used in esterification reactions of PFAD with methanol, an increase in conversion as enzyme concentration increased up to $9 \mathrm{wt} . \%$ has been observed, achieving a conversion of $73.8 \%$. For the reactions conducted with Novozym 435 , conversions above $93 \%$ were obtained with only $1 \mathrm{wt} . \%$ of enzyme. However, under the same conditions ( $1 \mathrm{wt} . \%)$, Lipozyme RM-IM enabled a lower conversion $(45 \%)$.

The effect of the concentration of lipase (0.1 to $9 \mathrm{wt} . \%$ ) was also evaluated in reactions carried out with ethanol 


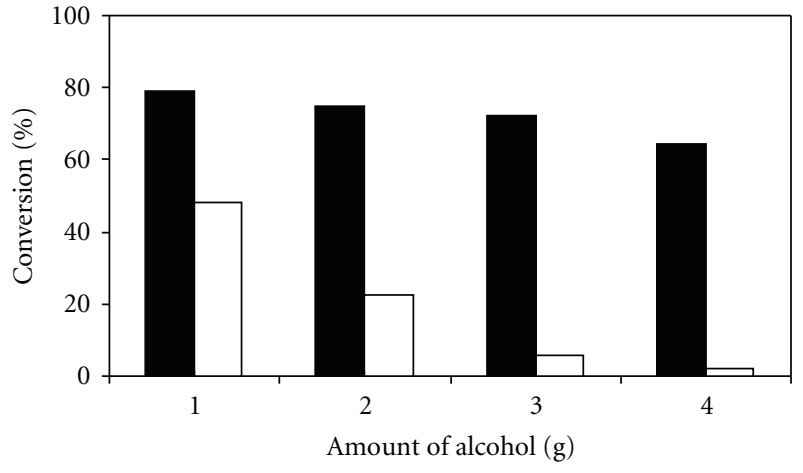

- Novozym 435

๑ Lipozyme RM-IM

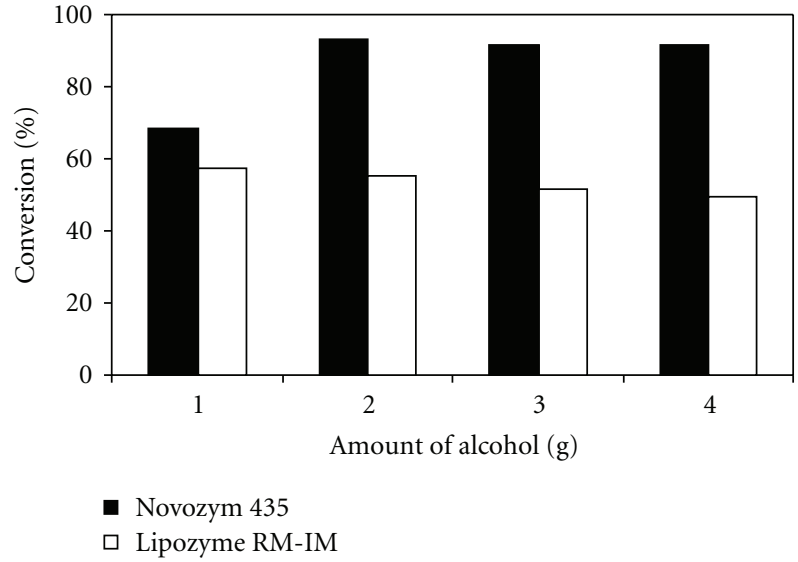

(b) Ethanol

FIGURE 2: Effects of alcohol amount on fatty acids conversion after $2.5 \mathrm{~h}$ of reaction, using a single addition of the alcohol at the beginning of reaction, 3 wt. $\%$ of commercial lipase, and $8 \mathrm{~g}$ of PFAD at $60^{\circ} \mathrm{C}$. (a) Methanol; (b) ethanol.

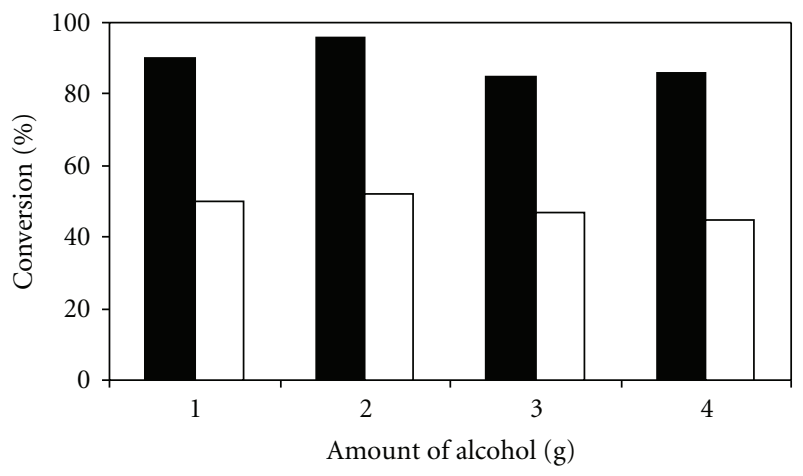

- Novozym 435

ㄴ Lipozyme RM-IM

(a) Methanol

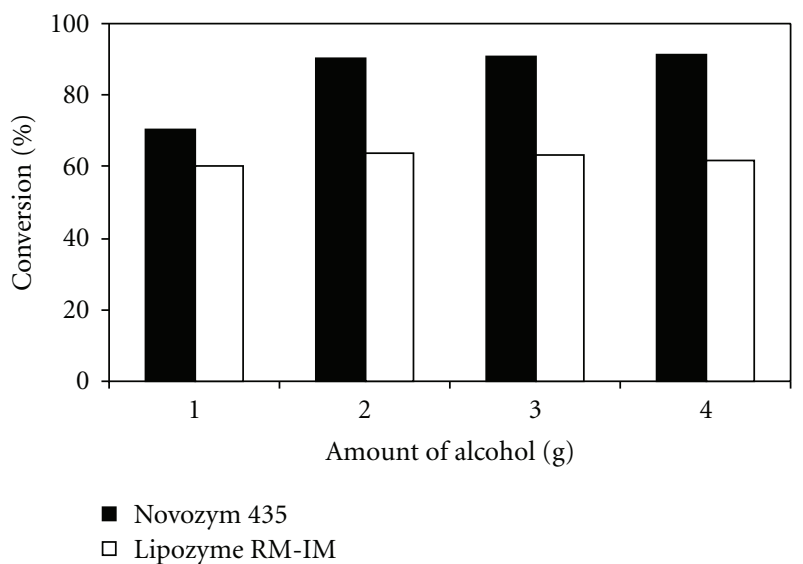

(b) Ethanol

FIGURE 3: Effects of alcohol amount on fatty acids conversion after $2.5 \mathrm{~h}$ of reaction, using a stepwise addition of alcohol (two consecutive alcohol additions, i.e. $1 / 2$ of alcohol added at time 0 and $1 / 2$ after 30 minutes), $3 \mathrm{wt} . \%$ of commercial lipase, and $8 \mathrm{~g}$ of PFAD at $60^{\circ} \mathrm{C}$. (a) Methanol; (b) ethanol.

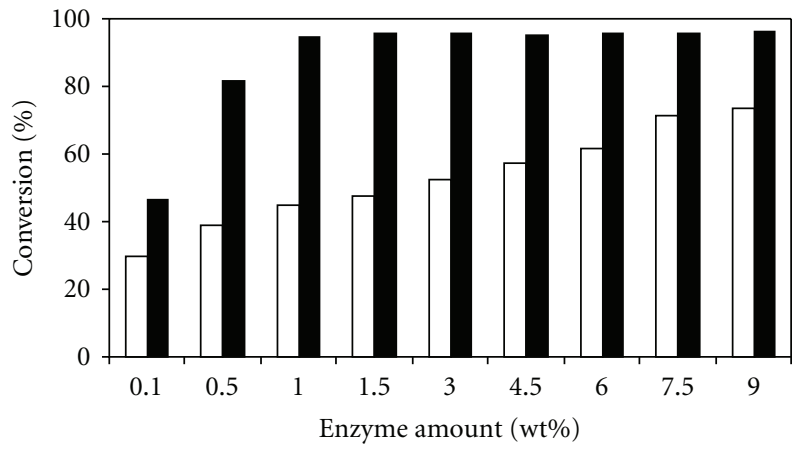

$\square$ Lipozyme RM-IM

- Novozym 435

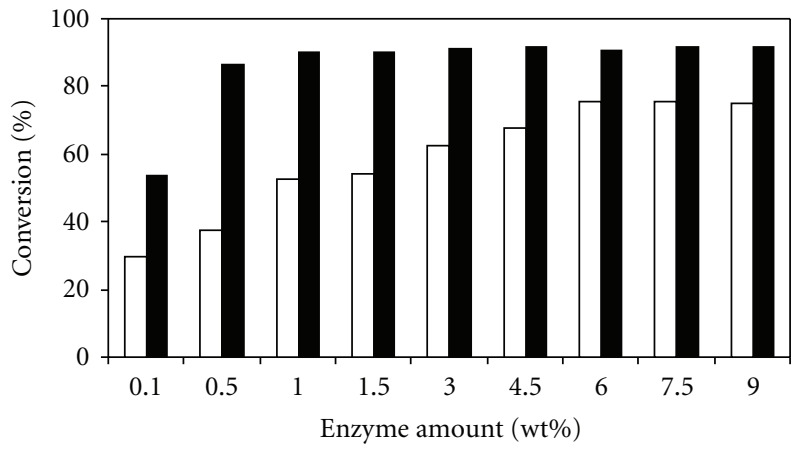

Lipozyme RM-IM

- Novozym 435

(a) Methanol

(b) Ethanol

FIGURE 4: Effects of enzyme amount on fatty acids conversion after $2.5 \mathrm{~h}$, using $8 \mathrm{~g}$ of PFAD and $2 \mathrm{~g}$ of ethanol added in two steps $\left(T_{0}=1.0 \mathrm{~g}\right.$, $T_{30 \min }=1.0 \mathrm{~g}$ ) at $60^{\circ} \mathrm{C}$. (a) Methanol; (b) ethanol. 


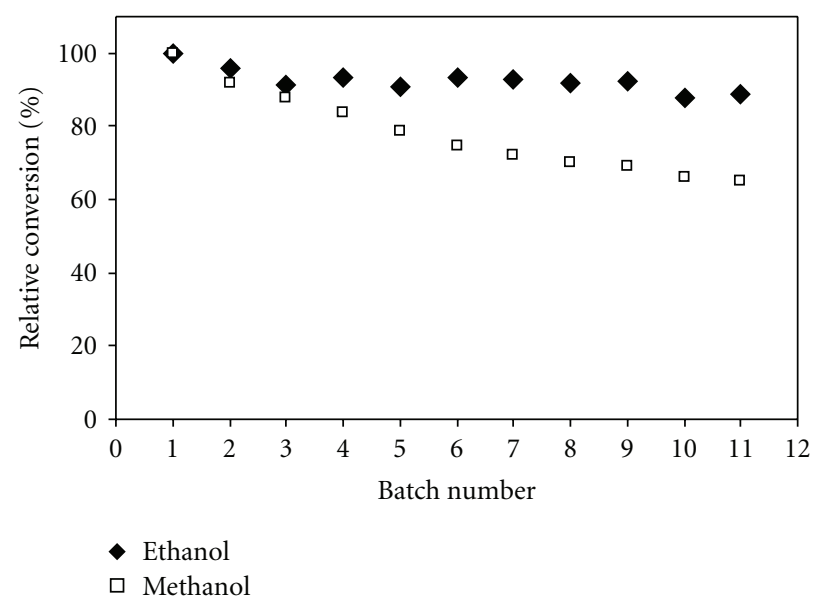

(a) Novozym 435

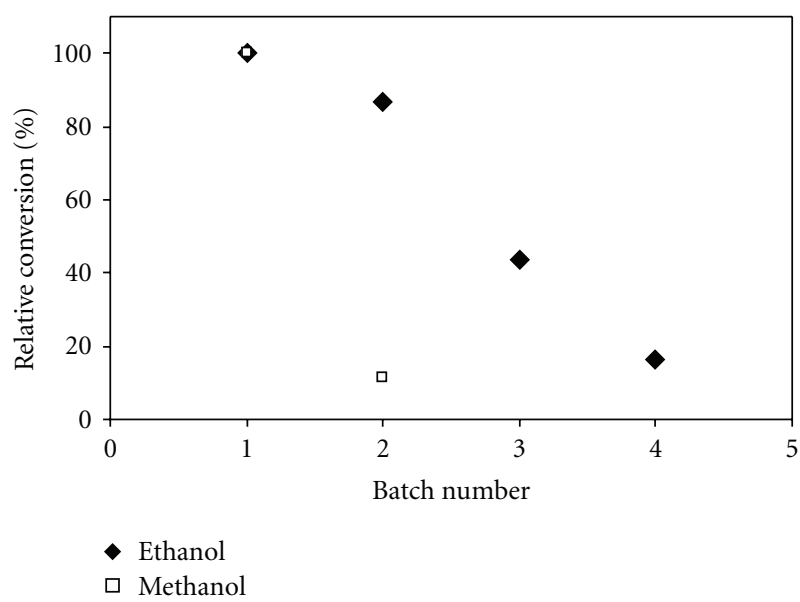

(b) Lipozyme RM-IM

FIGURE 5: Effects of enzyme reuse on relative fatty acids conversion. All of reactions were carried out for $2.5 \mathrm{~h}$, using $8 \mathrm{~g}$ of PFAD and $2 \mathrm{~g}$ of alcohol added in two steps $\left(T_{0}=1.0 \mathrm{~g}, T_{30} \min =1.0 \mathrm{~g}\right)$ at $60^{\circ} \mathrm{C}$. (a) Novozym 435; (b) Lipozyme RM-IM.

(Figure 4(b)). With Lipozyme RM-IM, an increase in conversion with increasing enzyme amount up to $6 \mathrm{wt} . \%$ was observed, achieving a conversion of $75.5 \%$. Higher amounts of enzyme did not result in a significant increase in conversion. For the reactions conducted with Novozym 435 , conversions of $86.7 \%$ were obtained with only $0.5 \mathrm{wt} . \%$ of enzyme. The initial rate values for the reactions using $0.5\left(2.59 \mu \mathrm{mol} \cdot \mathrm{min}^{-1}\right)$ and $9 \mathrm{wt} . \%\left(2.79 \mu \mathrm{mol} \cdot \mathrm{min}^{-1}\right)$ of Novozym 435 were similar. Thus, no significant increase in initial rate was observed when the loading of Novozym 435 increased from 0.5 to $9 \%$, which is interesting from an economic point of view. Despite Novozym 435 is more expensive than Lipozyme RM-IM, it presents a higher activity and can be used in smaller quantities than Lipozyme RM-IM to obtain higher conversions.

Talukder et al. [25] studied the production of biodiesel from PFAD using Novozym 435 in the range of 0.5-6.0 wt.\% of PFAD. The minimum amount of Novozym 435 required for obtaining the maximum biodiesel yield ( $>80 \%)$ was 1.0 wt. $\%$ in relation to PFAD amount.

3.5. Lipase Reuse. One of the main drawbacks of the use of enzymes for biodiesel production is the cost of the biocatalyst. Thus, several studies are reported in the literature investigating the reuse of immobilized lipases or continuous processes employing a system of packed-bed columns with immobilized lipases [26]. Therefore, the reuse of Lipozyme RM-IM and Novozym 435 was investigated in this work in the reactions carried out with $8 \mathrm{~g}$ of PFAD and $1 \mathrm{~g}$ of alcohol (methanol or ethanol), added in a stepwise manner $\left(T_{0}=\right.$ $0.5 \mathrm{~g}, \mathrm{~T}_{30 \mathrm{~min}}=0.5 \mathrm{~g}$ ), at $60^{\circ} \mathrm{C}$. Figure 5 shows the relative fatty acid conversion in each cycle.

It can be seen in Figure 5 that Novozym 435 remains active after more cycles than Lipozyme RM-IM and that methanol has a much more deleterious effect on lipase activity than ethanol, mainly for Lipozyme RM-IM, confirming the results previously observed in Section 3.3. Novozym
435 was reused 10 times with conversion reaching $88 \%$ and $65 \%$ after the eleventh reaction with ethanol and methanol, respectively. However, the fatty acid conversion was decreasing with successive use of Lipozyme RM-IM. Only $16 \%$ and $11 \%$ of fatty acid conversion was obtained after the third and the first reuse of Lipozyme RM-IM in the esterification reaction of ethanol and methanol, respectively. These results could be attributed to lipase denaturation caused by short-chain alcohols [27].

3.6. Biodiesel Production. A comparison between Novozym 435 and Lipozyme RM-IM was also evaluated using the same esterification activity units (2,000 U). The use of the same activity units values resulted in employing different amounts of Novozym 435 (0.68 g) and Lipozyme RM-IM (1.32 g) in esterification reactions of PFAD. These reactions were performed at $60^{\circ} \mathrm{C}$ with stepwise addition of alcohol $\left(T_{0}=\right.$ $1.0 \mathrm{~g}, T_{30 \mathrm{~min}}=1.0 \mathrm{~g}$ ). Under these conditions, biodiesel yield and fatty acids conversion were similar for both enzymes tested, as can be seen in Figure 6, confirming the higher esterification activity of Novozym 435, which results in the use of smaller amount of this enzyme preparation.

Both biodiesel yield and fatty acids conversion have the same profile during $2.5 \mathrm{~h}$ of reaction indicating that consumption of fatty acids was really for the production of FAME or FAEE. Biodiesel yield was higher than $80 \%$ after $2 \mathrm{~h}$ of reaction in these conditions. These results are similar to those reported by Talakuder et al. [25] who obtained $90 \%$ of biodiesel yield after $2 \mathrm{~h}$, at $60^{\circ} \mathrm{C}$, using Novozym. Wang et al. [11] have used a mixture of commercial lipases $(3 \%$ of Lipozyme TL-IM and 2\% of Novozym 435) in SODD esterification reaction with methanol, employing t-butanol as solvent, and they have obtained a yield of $84 \%$ in methyl esters after $12 \mathrm{~h}$.

The PFAD fatty acids esterification has been also studied using homogeneous acid catalyst. Chongkhong et al. [12] obtained more than $90 \%$ of FAME content (wt.\%) after $4 \mathrm{~h}$ 


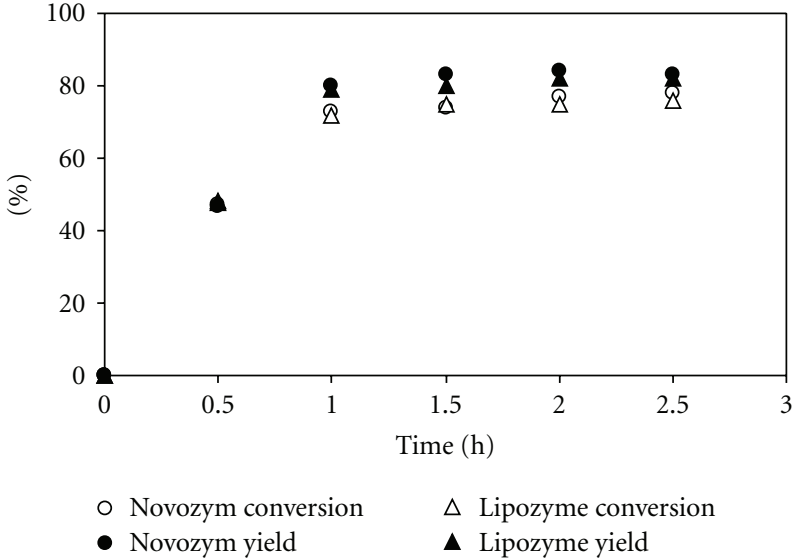

(a) Methanol

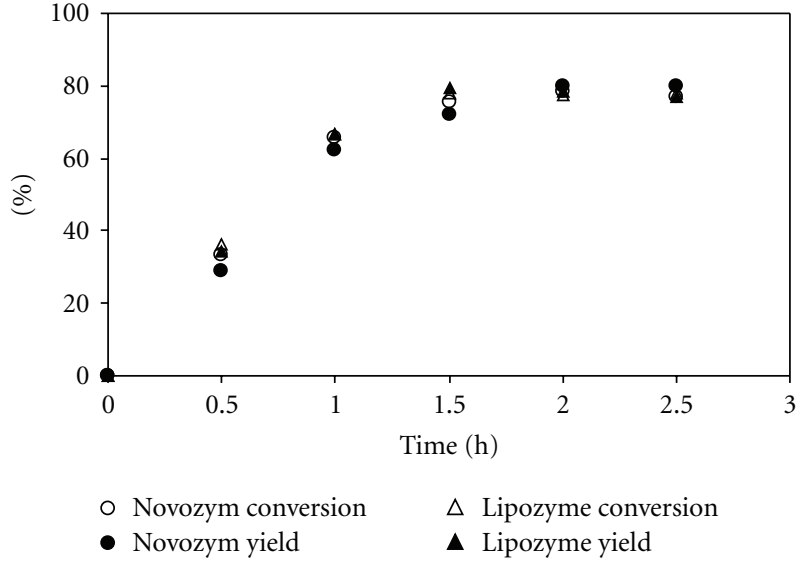

(b) Ethanol

FIGURE 6: Biodiesel yield and fatty acids conversion in enzymatic esterification of PFAD. All of reactions were carried out for $2.5 \mathrm{~h}$, using $2000 \mathrm{U}$ (esterification activity of lipase), $8 \mathrm{~g}$ of PFAD, and $2 \mathrm{~g}$ of alcohol added in two steps $\left(T_{0}=1.0 \mathrm{~g}, T_{30} \mathrm{~min}=1.0 \mathrm{~g}\right)$ at $60^{\circ} \mathrm{C}$. (a) Methanol; (b) ethanol.

of PFAD esterification with methanol, at $90^{\circ} \mathrm{C}$, with a molar ratio of methanol to PFAD higher than 4 , in the presence of 1.834 wt. $\%$ of $\mathrm{H}_{2} \mathrm{SO}_{4}$. When a molar ratio of methanol to PFAD equal to 1 was used, less than $70 \mathrm{wt} . \%$ of FAME was obtained.

Thus, the use of lipase for the biodiesel production from a byproduct of palm oil industry offers some advantages in relation to chemical catalysis. The immobilized lipase could be recovered and reused for several cycles by a simple procedure. Moreover, in the chemical process with $\mathrm{H}_{2} \mathrm{SO}_{4}$ [12], an increase of dark color of product occurred when the temperature increased. This dark color was not observed in enzymatic reactions. The homogeneous acid catalyzed esterification also presents difficulties in biodiesel purification, catalyst recovery, and wastewater treatment [25]. Finally, high yields were achieved in enzymatic process by using smaller amounts of alcohol.

\section{Conclusions}

The biodiesel synthesis using a byproduct from palm oil refining and commercial immobilized lipases was demonstrated in this work. High fatty acids conversions were obtained in mild reaction conditions. Biodiesel yields higher than $80 \%$ were obtained in the reactions conducted with methanol or ethanol employing Novozym 435. The use of such a cheap feedstock and a biocatalyst to produce biodiesel, in addition to economic gains, represents an environment friendly process.

\section{Acknowledgment}

The authors would like to acknowledge Cenpes-Petrobras, FAPERJ, and $\mathrm{CNPq}$ for financial support and Novozymes Latin America Ltda. for kindly providing enzymes for this research.

\section{References}

[1] L. C. Meher, D. V. Sagar, and S. N. Naik, "Technical aspects of biodiesel production by transesterification-a review," Renewable and Sustainable Energy Reviews, vol. 10, no. 3, pp. 248-268, 2006.

[2] M. G. Kulkarni and A. K. Dalai, "Waste cooking oil-an economical source for biodiesel: a review," Industrial and Engineering Chemistry Research, vol. 45, no. 9, pp. 2901-2913, 2006.

[3] M. S. Souza, E. C. G. Aguieiras, M. A. P. Da Silva, and M. A. P Langone, "Biodiesel synthesis via esterification of feedstock with high content of free fatty acids," Applied Biochemistry and Biotechnology, vol. 154, no. 1-3, pp. 74-88, 2009.

[4] M. J. Dumont and S. S. Narine, "Soapstock and deodorizer distillates from North American vegetable oils: review on their characterization, extraction and utilization," Food Research International, vol. 40, no. 8, pp. 957-974, 2007.

[5] C. F. Torres, G. Torrelo, F. J. Señorans, and G. Reglero, "A two steps enzymatic procedure to obtain sterol esters, tocopherols and fatty acid ethyl esters from soybean oil deodorizer distillate," Process Biochemistry, vol. 42, no. 9, pp. 1335-1341, 2007.

[6] S. Gunawan, N. S. Kasim, and Y. H. Ju, "Separation and purification of squalene from soybean oil deodorizer distillate," Separation and Purification Technology, vol. 60, no. 2, pp. 128135,2008 .

[7] C. F. Torres, A. M. Toré, T. Fornari, F. J. Señoráns, and G. Reglero, "Ethanolysis of a waste material from olive oil distillation catalyzed by three different commercial lipases: a kinetic study," Biochemical Engineering Journal, vol. 34, no. 2, pp. 165-171, 2007.

[8] H. Yang, F. Yan, D. Wu et al., "Recovery of phytosterols from waste residue of soybean oil deodorizer distillate," Bioresource Technology, vol. 101, no. 5, pp. 1471-1476, 2010.

[9] M. A. Carmona, C. Jiménez, C. Jiménez-Sanchidrián, F. Peña, and J. R. Ruiz, "Isolation of sterols from sunflower oil deodorizer distillate," Journal of Food Engineering, vol. 101, no. 2, pp. 210-213, 2010.

[10] Y. Liu, L. Wang, and Y. Yan, "Biodiesel synthesis combining pre-esterification with alkali catalyzed process from rapeseed 
oil deodorizer distillate," Fuel Processing Technology, vol. 90, no. 7-8, pp. 857-862, 2009.

[11] L. Wang, W. Du, D. Liu, L. Li, and N. Dai, "Lipase-catalyzed biodiesel production from soybean oil deodorizer distillate with absorbent present in tert-butanol system," Journal of Molecular Catalysis B, vol. 43, no. 1-4, pp. 29-32, 2006.

[12] S. Chongkhong, C. Tongurai, P. Chetpattananondh, and C. Bunyakan, "Biodiesel production by esterification of palm fatty acid distillate," Biomass \& Bioenergy, vol. 31, no. 8, pp. 563-568, 2007.

[13] S. Chongkhong, C. Tongurai, and P. Chetpattananondh, "Continuous esterification for biodiesel production from palm fatty acid distillate using economical process," Renewable Energy, vol. 34, no. 4, pp. 1059-1063, 2009.

[14] Y. Liu and L. Wang, "Biodiesel production from rapeseed deodorizer distillate in a packed column reactor," Chemical Engineering and Processing, vol. 48, no. 6, pp. 1152-1156, 2009.

[15] A. G. M. Top, "Production and utilization of palm fatty acid distillate (PFAD)," Lipid Technology, vol. 22, no. 1, pp. 11-13, 2010.

[16] F. Hasan, A. A. Shah, and A. Hameed, "Industrial applications of microbial lipases," Enzyme and Microbial Technology, vol. 39, no. 2, pp. 235-251, 2006.

[17] M. G. De Paola, E. Ricca, V. Calabrò, S. Curcio, and G. Iorio, "Factor analysis of transesterification reaction of waste oil for biodiesel production," Bioresource Technology, vol. 100, no. 21, pp. 5126-5131, 2009.

[18] Official Methods and Recommended Practices of the American Oil Chemists' Society, AOCS, Champaign, Ill, USA, 5th edition, 1998.

[19] G. Knothe, "Structure indices in FA chemistry. How relevant is the iodine value?" Journal of the American Oil Chemists Society, vol. 79, no. 9, pp. 847-854, 2002.

[20] The Merck Index, Merck \& Co, Whitehouse Station, NJ, USA, 14th edition, 2006.

[21] A. Robles-Medina, P. A. González-Moreno, L. EstebanCerdán, and E. Molina-Grima, "Biocatalysis: towards ever greener biodiesel production," Biotechnology Advances, vol. 27, no. 4, pp. 398-408, 2009.

[22] R. C. Rodrigues and R. Fernandez-Lafuente, "Lipase from Rhizomucor miehei as a biocatalyst in fats and oils modification," Journal of Molecular Catalysis B, vol. 66, no. 1-2, pp. 15-32, 2010.

[23] Y. Liu, H. Tan, X. Zhang, Y. Yan, and B. H. Hameed, "Effect of monohydric alcohols on enzymatic transesterification for biodiesel production," Chemical Engineering Journal, vol. 157, no. 1, pp. 223-229, 2010.

[24] R. Fernandez-Lafuente, "Lipase from thermomyces lanuginosus: uses and prospects as an industrial biocatalyst," Journal of Molecular Catalysis B, vol. 62, no. 3-4, pp. 197-212, 2010.

[25] M. M. R. Talukder, J. C. Wu, S. K. Lau, L. C. Cui, G. Shimin, and A. Lim, "Comparison of novozym 435 and amberlyst 15 as heterogeneous catalyst for production of biodiesel from palm fatty acid distillate," Energy \& Fuels, vol. 23, no. 1, pp. 1-4, 2009.

[26] P. M. Nielsen, J. Brask, and L. Fjerbaek, "Enzymatic biodiesel production: technical and economical considerations," European Journal of Lipid Science and Technology, vol. 110, no. 8, pp. 692-700, 2008.

[27] A. Bajaj, P. Lohan, P. N. Jha, and R. Mehrotra, "Biodiesel production through lipase catalyzed transesterification: an overview," Journal of Molecular Catalysis B, vol. 62, no. 1, pp. 9-14, 2010. 

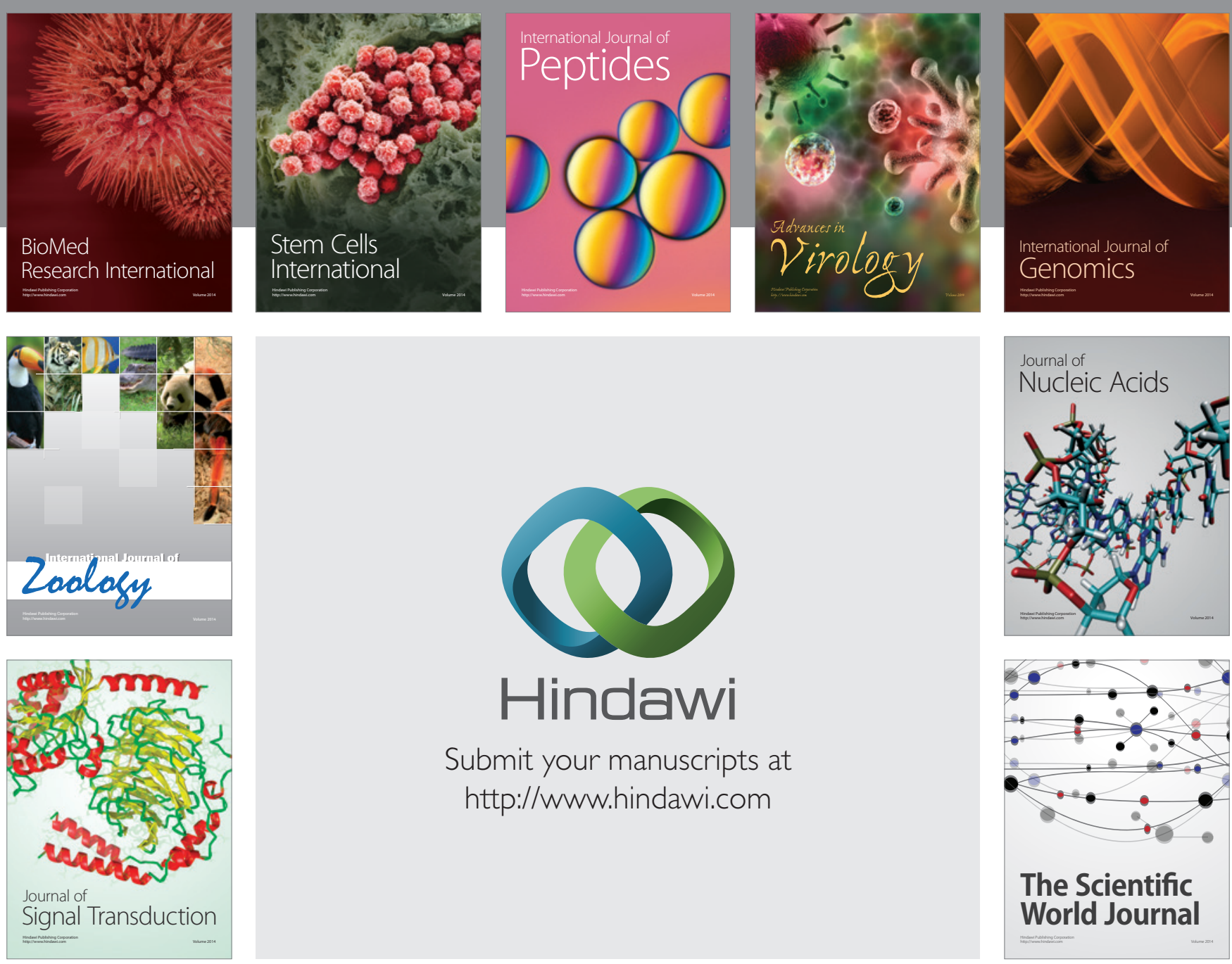

Submit your manuscripts at

http://www.hindawi.com
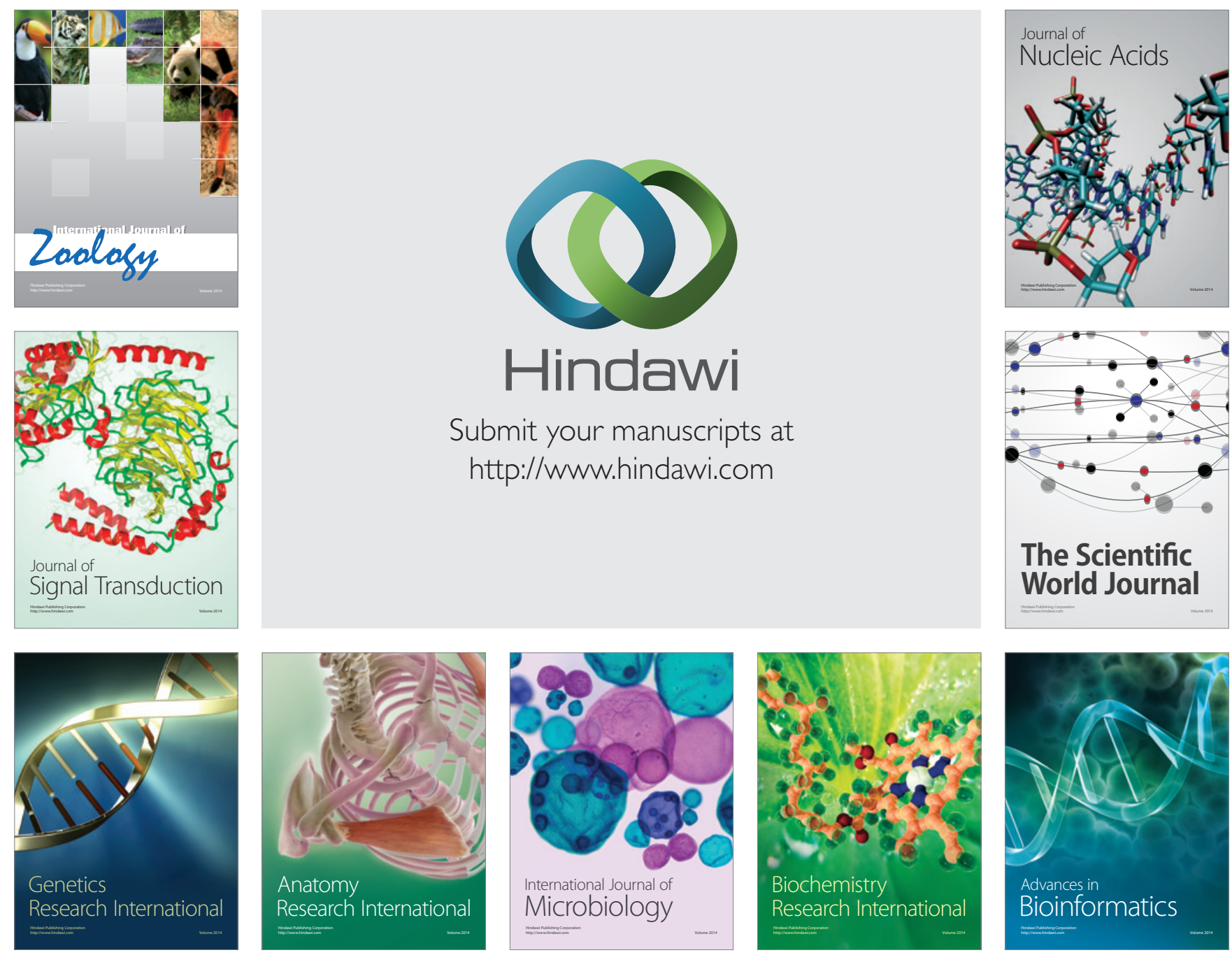

The Scientific World Journal
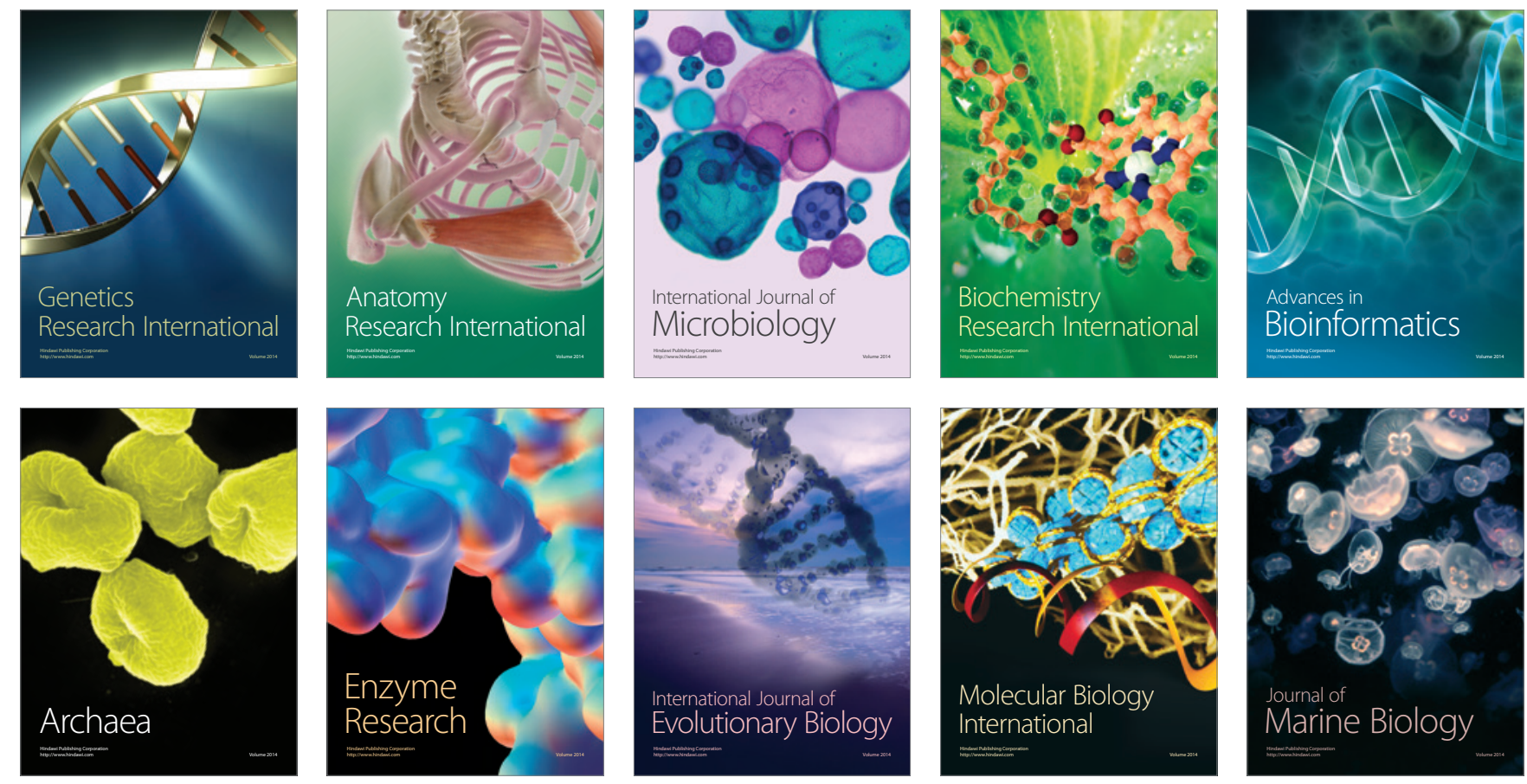